Document downloaded from:

http://hdl.handle.net/10251/49040

This paper must be cited as:

Ivan Tobón, J.; Paya Bernabeu, JJ.; Borrachero Rosado, MV.; Soriano Martinez, L.; Restrepo Baena, OJ. (2012). Determination of the optimum parameters in the high resolution thermogravimetric analysis (HRTG) for cementitious materials. Journal of Thermal Analysis and Calorimetry. 107:233-239. doi:10.1007/s10973-010-0997-0.

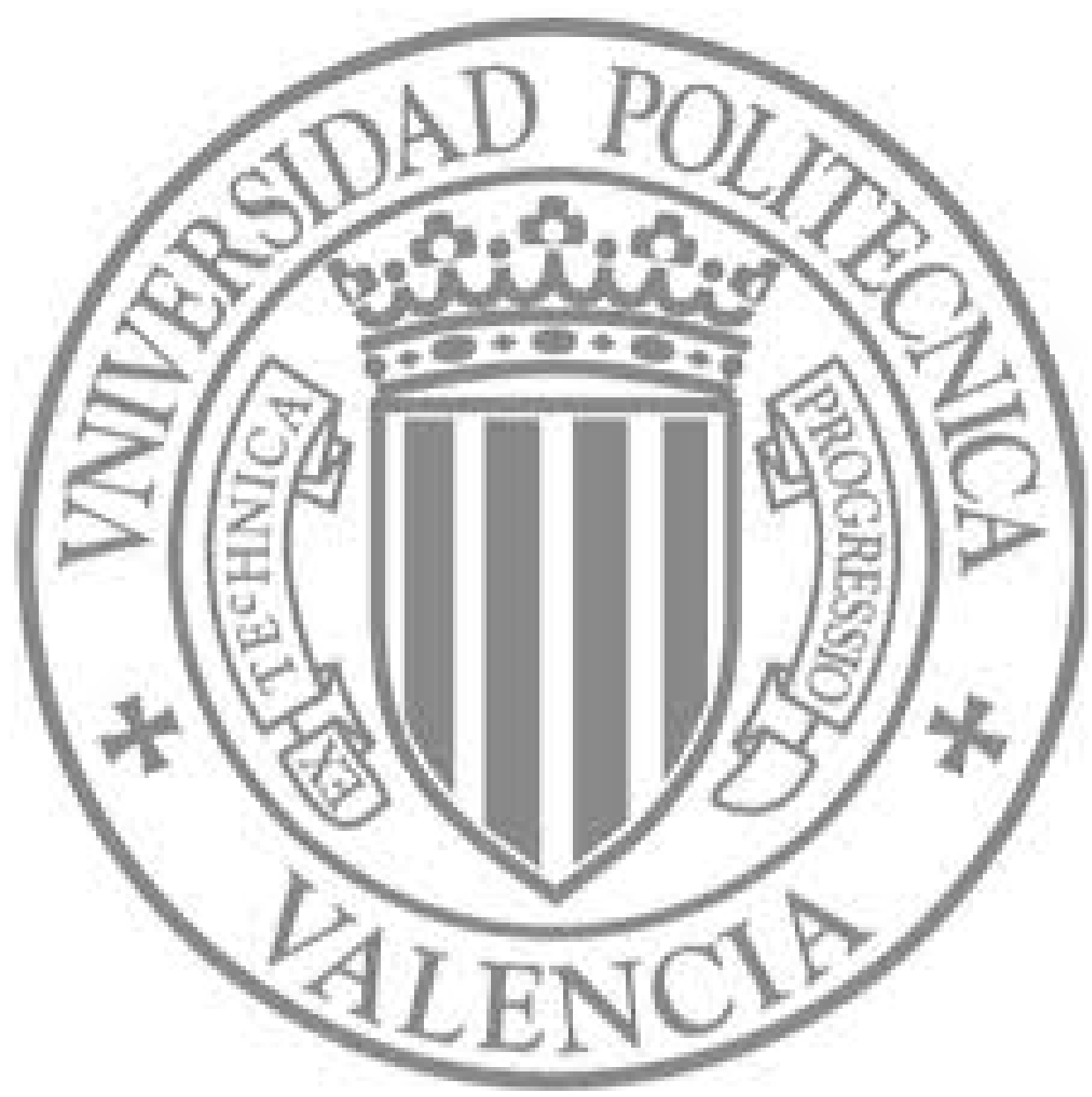

The final publication is available at

http://dx.doi.org/10.1007/s10973-010-0997-0

Copyright Springer 


\title{
DETERMINATION OF THE OPTIMUM PARAMETERS IN THE HIGH RESOLUTION THERMOGRAVIMETRIC ANALYSIS FOR CEMENTITIOUS MATERIALS
}

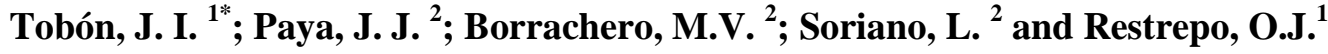 \\ ${ }^{1}$ Grupo del Cemento y Materiales de Construcción - Universidad Nacional de Colombia \\ ${ }^{2}$ Instituto de Ciencia y tecnología del Hormigón (ICITECH) - Universidad Politécnica de Valencia - España \\ *E-Mail: jitobon@unal.edu.co
}

\begin{abstract}
In this paper the methodology to utilization of High Resolution Thermogravimetric (HRTG) software for construction materials like Portland cement pastes is presented. The aim of this technique is to make easier the changes identification of the decomposition reactions that frequently are overlapping on conventional Thermogravimetric Analysis (TG). The optimum parameters about sample mass and purge flow gas were established. It is necessary to work with high quantity of sample and without purge gas was concluded in order to get better results and excellent reproducibility. The tests have average velocity higher to $3{ }^{\circ} \mathrm{C} \cdot \mathrm{min}^{-1}$ in the temperature range selected $\left(35-300^{\circ} \mathrm{C}\right)$, it shows that the $\mathrm{HRTG}$ is not an expensive spent-time technique.
\end{abstract}

Keyword: High Resolution Thermogravimetry, portland cement, dehydration

\section{INTRODUCTION}

Thermogravimetric analysis (TG) and its first derivative (DTG) and Differential thermal analysis ( DTA) becomes techniques widely employed in the identification of the mineral phases or compositional analysis in materials such as clay, plaster casts, limes, gypsum and cements, among others [1-5]. In addition, TG technique enable the quantification of the minerals present determining the weight lost by the different decomposition reactions that may occur, such as dehydration, combustion, dehydroxilation, etc [6].
The great disadvantage of this technique is that is very common to find that different minerals have very close change phases or decomposition temperature, with overlapping peaks in the DTG thermogram.

To resolve this phenomenon is common to resort to the decline of the heating rate (less than $\left.0.5{ }^{\circ} \mathrm{C} \cdot \mathrm{min}^{-1}\right)$, looking for quasiisothermal conditions during the reactions of interest. Of this way it can get a better resolution in the thermogram. This improvement in resolution occurs if the rate of reaction and the respective activation energy are sufficiently different $[7,8]$. The problem is that since the heating rate is constant the analysis costs rise significantly, by hours of use of the equipment, making the technique economically unfeasible. 
These thermal analysis techniques (DTA, TG and DTG) have been used to analyze hydrated cement pastes $[9,10]$. For these materials, one of the most important analytical parameters is the water released from calcium hydroxide (dehydroxilation). In this case these analyses are used to evaluate cement based materials containing pozzolanic additions. The pozzolanic activity is measured from the calcium hydroxide consumption by pozzolan forming additionally similar hydrated products than those produced from the hydration of cement [11-13].

When a sample of hydrated Portland cement paste is analyzed, decomposition of "minerals" as tobermorite, ettringite and gypsum often show overlapped peaks in the temperature range $100-180^{\circ} \mathrm{C}$, because their reactions occur practically consecutive and the constant heating rate of the conventional TG impedes their differentiation. In these cases, in DTG curve, usually peaks widened or with shoulders are found because signal (mass loss rate) between two processes fails to return to the base line (null weight loss rate), which prevents accurate recognition of phases and quantification of these.

Different strategies have been proposed in order to solve these behaviour. Dweck et al [14] present a method to study cement hydration at ambient temperatures by using a micro processes non-conventional differential thermal analysis (DTA) system.

Criado et al [15] develop an alternative method applied to inorganic products, called "Constant Rate Thermal Analysis" (CRTA) that implies achieving a temperature profile at which the reaction rate remains constant all over the process at a value previously selected by the user.

In the dehydration of cement paste, the overlapped peaks in the temperature range $100-180^{\circ} \mathrm{C}$ could be resolved using the maximum resolution (MaxRes ${ }^{\mathrm{TM}}$ ) or High Resolution (Hi-Res ${ }^{\mathrm{TM}}$ ) modules available in machines of some brands thermal analysis software. This specific software enables the compositional analysis faster without losing resolution $[7,16]$.

Construction materials, such as the Portland cement pastes, are particularly complex to perform their thermogravimetric analysis because the reaction products are not stoichiometric compounds. This fact, together with the overlapping in some of the decay processes, makes these materials excellent systems to be scanned using High-Resolution Thermogravimetry (HRTG) technique, but little has been reported about this subject.

\section{BASIC CONCEPTS}

High Resolution Thermogravimetry (HRTG) technique enables the TG analysis in a dynamic manner because the heating rate of the sample, depending on its weight loss, can be scheduled regardless of the processes involved and its kinetics [1]. In this way, it is possible achieve shorter testing time with improved resolution in comparison to the conventional TG. On the software parameters are defined as:

- Minimum and maximum rate of heating (in ${ }^{\circ} \mathrm{C} \cdot \mathrm{min}^{-1}, \quad \mathrm{~V}_{\min }$ and $\mathrm{V}_{\max }$ ).

- Highest and lowest weight loss threshold (in $\mu \mathrm{g} . \mathrm{s}^{-1}, \mathrm{~W}_{\max }, \mathrm{W}_{\min }$ ) to modify the heating rate.

- Value Factor (f) and timeout (t).

- Temperature Range.

Essentially software enables begin with maximum warming speed $\left(\mathrm{V}_{\max }\right)$ and when it found that the lowest weight loss threshold $\left(\mathrm{W}_{\min }\right)$ is exceeded the heating rate decreases in given factor (f), meets timeout (t) and again evaluates the progress of weight loss. If the condition is preserved, 
the heating rate is again dropped in the same factor. This continues until it reaches the minimum established speed of warming $\left(\mathrm{V}_{\min }\right)$ or when maximum speed weight loss $\left(\mathrm{W}_{\max }\right)$ threshold value is exceeded. The resulting temperature program is a set of dynamic segments [7]. Thus breaks observed in the thermogram are more vertical and the overlapping decreases among consecutive and close process, since the decomposition occurs almost in quasiisothermal conditions, significantly facilitating its evaluation [1].

HRTG technique and all modifications developed to improve resolution, based on the heating rate decreased presented as main constraint that events cannot be separated if the second overlapped reaction activation energy is much larger than the first one. In these cases methods or conditions must be modified, such as to change gas or pressure [7].

\section{METHODS AND MATERIALS}

Spanish Portland cement (CEM I 52.5R) paste samples blended with $10 \%$ a high reactivity siliceous pozzolan (Nyasil) to 28 days of normal curing were analyzed for this work. Adding this pozzolan aims to generate a large amount and diversity of hydrated products. The pastes were prepared with a relationship water/binder 0,4 and pozzolan/cement ratio was $1 / 9$. To 28 days the curing the samples were ground in the presence of acetone, leaked and the resulting solid dried in oven at $60{ }^{\circ} \mathrm{C}$ for 30 minutes.

In a Thermoscale TGA 850 Mettler-Toledo the samples were analyzed, $100 \mu \mathrm{L}$ with perforated sellable lid aluminum crucibles (allowing that into crucible an selfatmosphere to be generate from water vapor released by the sample: self-generate atmosphere) and dry $\mathrm{N}_{2}$ as purge gas were used.

Followings parameters to perform tests on the thermogravimetry machine were chosen:

- Minimal heating rate

$$
\mathrm{V}_{\text {min }}: \quad 0,5^{\circ} \mathrm{C} \cdot \mathrm{min}^{-1}
$$

- Maximum heating rate

$$
\mathrm{V}_{\max }: \quad 10^{\circ} \mathrm{C} \cdot \min ^{-1}
$$

- threshold $\mathrm{W}_{\max }: 3 \mu \mathrm{g} \cdot \mathrm{s}^{-1}$

- threshold $\mathrm{W}_{\min }: 1 \mu \mathrm{g} . \mathrm{s}^{-1}$

- Factor f: 2

- Timeout t: $6 \mathrm{~s}$

- Temperature Interval ${ }^{\circ} \mathrm{C}-300{ }^{\circ} \mathrm{C}$

\section{RESULTS AND DISCUSSION}

\subsection{COMPARISON BETWEEN HRTG AND CONVENTIONAL TG}

Figure 1 presents the curves to a same sample analyzed by conventionally Thermogravimetric analysis (TG, 10 ${ }^{\circ} \mathrm{C} \cdot \mathrm{min}^{-1}$ ) and by High Resolution (HRTG), with equal conditions $60 \mathrm{mg}$ sample weight, aluminium crucible of $100 \mu \mathrm{L}$ with pinhole cover lid and $75 \mathrm{ml} \mathrm{N}_{2} \cdot \mathrm{min}^{-1}$ purge gas.

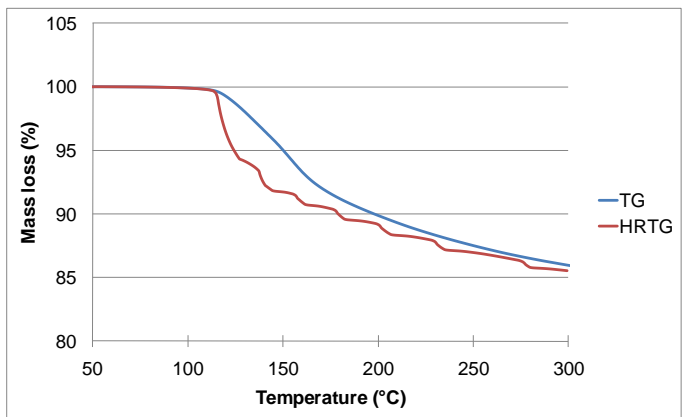

Figure 1. Thermogravimetric analysis curves; conventional (TG) versus high resolution (HRTG)

There is a clear different between the resolutions of two curves. In TG curve the mass loss is practically constant meanwhile that in HRTG there are much changes of slope, it shows different decomposition reaction in the temperature interval evaluated. These differences are clearer in DTG curves (Figure 2). 


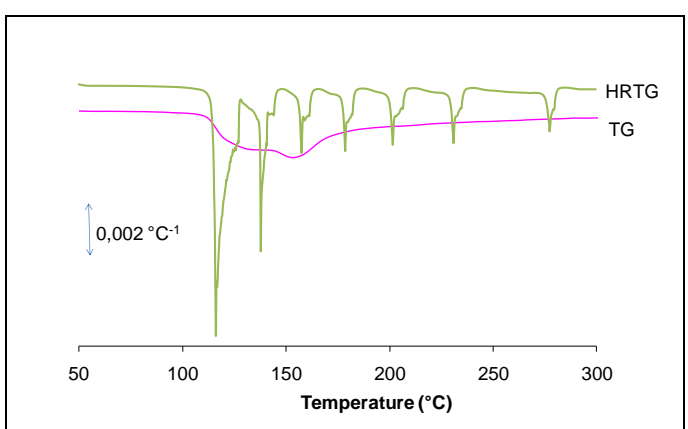

Figure 2. Comparison between a conventional TG test and a HRTG.

In HRTG curve with more detail each one of the decompositions (dehydration and dehydroxilation) that occur in the sample are resolved, for the range of studied temperature seven picks are obtained. The conventional TG displays only one peak ( $\mathrm{T}$ $\left.\approx 150{ }^{\circ} \mathrm{C}\right)$ with a shoulder $\left(\mathrm{T} \approx 130{ }^{\circ} \mathrm{C}\right)$. In the TG curve after $200{ }^{\circ} \mathrm{C}$ there is not any peak, only a drop in the rate of gradual weight loss.

The HRTG allows higher resolution of the events that occur during the heating of the sample. In Figure 1 It is possible see that this method detects up to 4 processes clearly differentiated in the region of the conventional TG detection and in the region where the TG does not detect any change ( $\mathrm{T}$ $>200{ }^{\circ} \mathrm{C}$ ) the HRTG registers three decomposition processes. This behavior is because in high-resolution technique the temperature remains almost constant during decomposition, for this reason, It has more possibilities to be registered.

It is important to stress that total weight loss by the two methods is virtually the same $(\mathrm{HRTG}=14,29 \%$ and $\mathrm{TG}=14,05$ $\%)$ (Figure 1).

\subsection{INFLUENCE OF THE PURGE GAS FLOW IN HRTG}

Figure 3 shows changes in the DTG curves obtained with high resolution varying purge gas flow. The gas changes were from 0
mL. $\min ^{-1}$ as many as $75 \mathrm{~mL} \cdot \mathrm{min}^{-1}$ of $\mathrm{N}_{2}$. All the others test condition were equals.

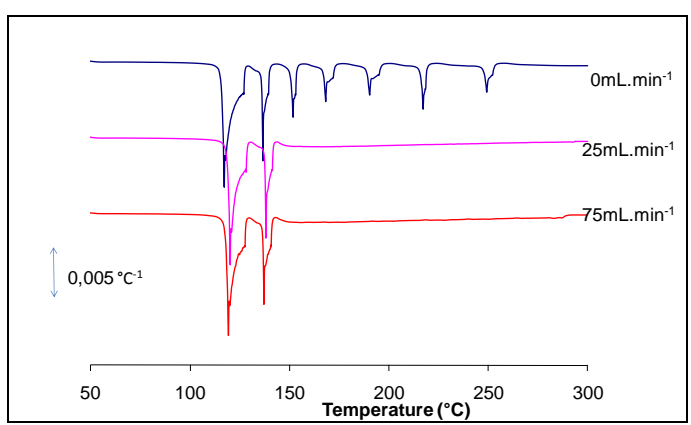

Figure 3. Variation of the DTG-HRTG curves with the purge gas flow

When the gas flow is null, the resolution increases and events of decomposition at temperatures higher than $145{ }^{\circ} \mathrm{C}$ may be detected. This fact is related to the formation of a self-generated atmosphere of water steam in the crucible. When there is gas flow, the gas running directly over the pinhole sealed lid of the crucible, and drag the steam generated in the decompositions. Thereby the pressure of water vapor in the interior of the crucible is reduced and not allow stabilize the different hydrates still existing in the sample. However, when no purge gases, the pressure of water vapor in the interior of the crucible is higher. This fact allows stabilize more hydrates remnants, to the point that it can see up to 5 peaks than in the previous cases.

It was found that when the purge gas was used in the tests the reproducibility was very low, unlike what happened without purge gas as will be seen later. In the experiments without purge gas normally appear in the thermograms biggest peaks quantity.

Table 1 shows the temperatures of the first two peaks in the curves. Elimination of the gas flow makes decomposition reaction is detected at temperatures slightly lower. Signals integration allows quantifying the amount of evaporated material. Table 1 shows that the weight lost in the first two 
reactions in the trial without purge gas is slightly greater.

Table 1. Variation of the DTG-HRTG curves with the purge gas flow

\begin{tabular}{|c|c|c|c|}
\hline Flow & Peak1 & Peak 2 & $\begin{array}{c}\text { Weight } \\
\text { lost (\%) }\end{array}$ \\
$\mathbf{N}_{\mathbf{2}}$ & ${ }^{\circ} \mathbf{C}$ & ${ }^{\circ} \mathbf{C}$ & \\
\hline $\mathbf{0}$ & 117,2 & 136,7 & 6,27 \\
\hline $\mathbf{2 5}$ & 120,2 & 138,2 & 5,83 \\
\hline $\mathbf{7 5}$ & 119,3 & 137,2 & 6,10 \\
\hline
\end{tabular}

In accordance with the preceding remarks we recommend make the tests without purge gas.

\subsection{INFLUENCE OF THE SAMPLE MASS ON THE THERMOGRAMS RESOLUTION.}

Figures 4 and 5 are, respectively, TG curves and DTG curves obtained applying the HRTG technique based on the variation mass of the hydrated cement. The same sample, under the same conditions (no purge gas), varying the mass of sample was analyzed. The mass increased from $10 \pm 1 \mathrm{mg}$ (sample c10) up to $60 \pm 1 \mathrm{mg}$ (sample c60).

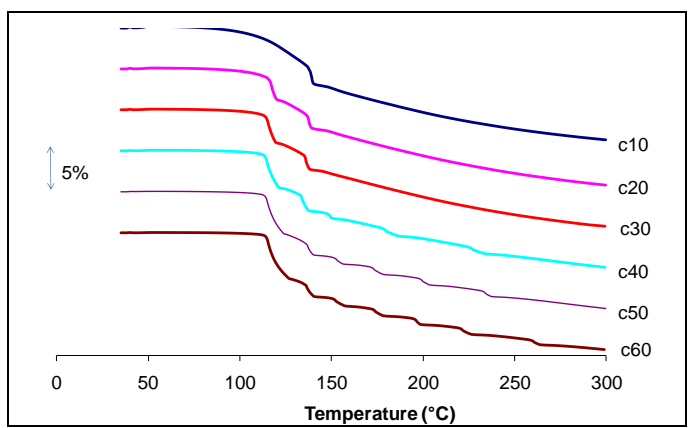

Figure 4. Changes in the thermogravitric curves HRTG with the variation of the sample mass.

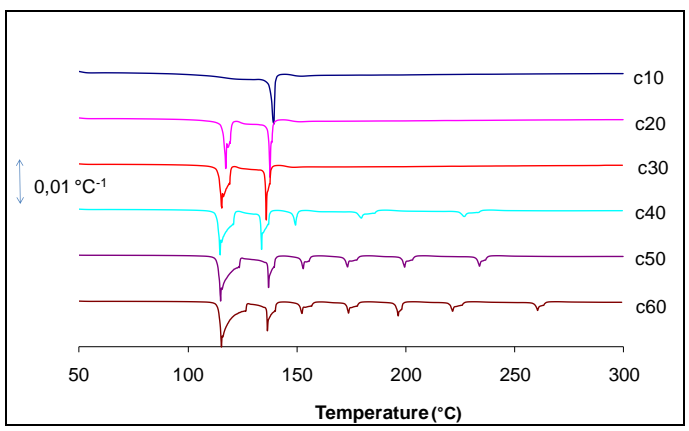

Figure 5. Changes in the DTG-HRTG curves with the variation of the samples mass.

An increase in the resolution of the thermograms insofar increasing the mass of the sample was evidenced. Samples with 40 $\mathrm{mg}, 50 \mathrm{mg}$ and $60 \mathrm{mg}$ have great similarity especially in the first two peaks (Figure 5) which are the mainly for these samples. To corroborate this total weight loss due to the decomposition of the sample until a temperature evaluated was calculated (Figure 6)

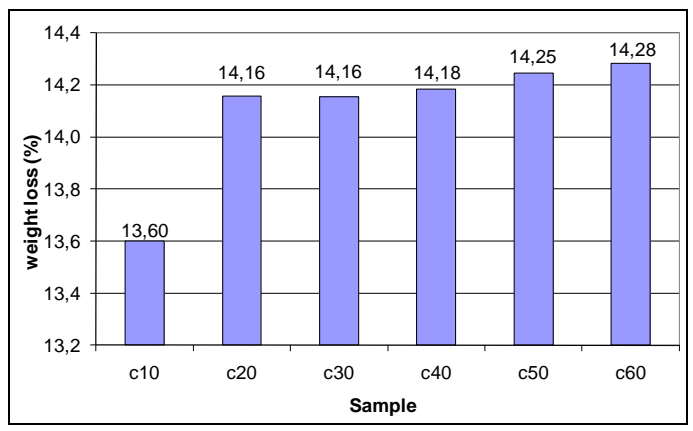

Figure 6. Total weight loss to vary the mass of the sample.

Weight loss shows an important error in the sample $10 \mathrm{mg}$ (4.7\%), which indicates that this amount is not appropriate for these analyses. Thereafter the difference in weight is minimal $(0.84 \%)$, being essentially equal the percentage in the weight loss to the samples $50 \mathrm{mg}$ and 60 $\mathrm{mg}$ with a difference of $0.2 \%$.

From the curve for the sample c60, can be calculated (Table 2) weight losses associated (in percentage, $\mathrm{X}_{\mathrm{i}}$ ) to each peak as well as temperatures of maximum weight loss rate (in ${ }^{\circ} \mathrm{C}, \mathrm{T}_{\mathrm{i}}{ }^{\mathrm{max}}$ ). Mass losses $\mathrm{X}_{\mathrm{i}}$ are 
calculated for each peak since the end of the previous event $\left(\mathrm{T}_{\mathrm{a}}\right)$ until the completion of the event considered $\left(\mathrm{T}_{\mathrm{b}}\right)$.

Table 2 shows that except for $\mathrm{C} 10$, in all other cases integration intervals remain very similar, i.e. that each process begins and ends for similar temperature. Beside, the position of the peaks $\left(\mathrm{T}_{\mathrm{i}}^{\mathrm{max}}\right)$ just varies and weight loss values change with the mass because the resolution is greater. Loss to peak 1 is increasing at the expense of the 2 peak, but the sum of two mass loss remain constant (Figure 7).

Table 2. Parameters of the peaks of the DTG

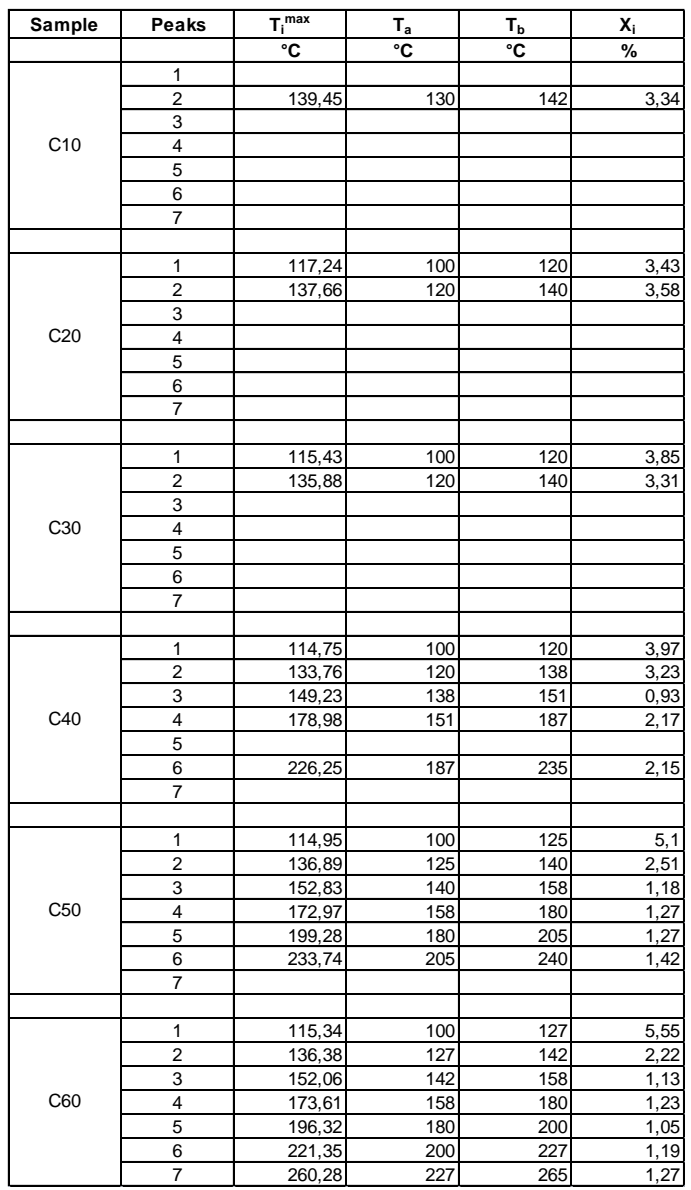

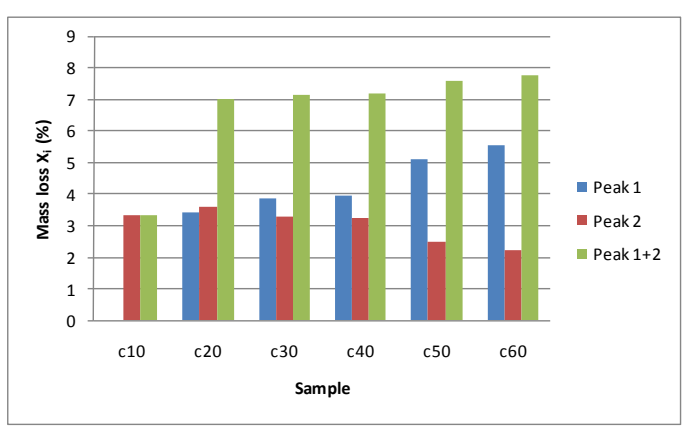

Figure 7. Mass loss samples in two first decompositions in HRTG with the variation of sample mass.

Figure 8 shows the variation in temperature with the time, for this same set of samples. In these curves the different changes in speed of warming can be viewed. Maximum gradient levels correspond to the maximum speed $\mathrm{V}_{\max }$ and sloping minimum to $\mathrm{V}_{\text {min }}$.

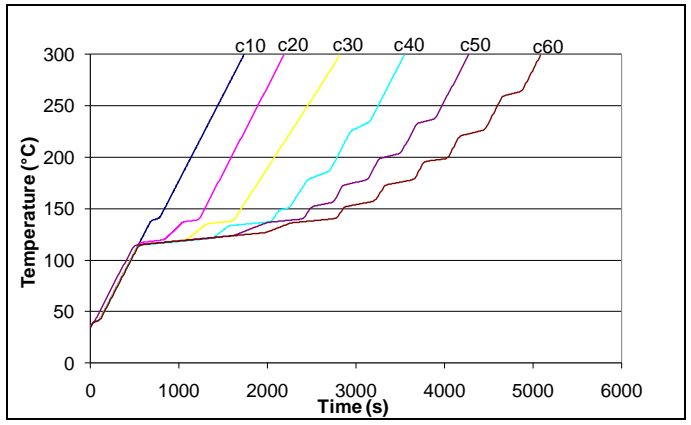

Figure 8. Variation in the temperature samples with the time.

The software changes the rate of increase in temperature on the loss of the sample mass. Thus, reactions involving little variation in the mass are almost imperceptible to the computer, so the heating rate tends to be constant and maximum (high slope in the graph) and when has been an increase in the loss of mass, product of the breakdown of any constituent phases of the sample, the heating rate decreases until the minimum. In the sample c60 equipment can detect a high number of decomposition reactions and even evaluates them to a rate less 
heating because in each weight loss is more noticeable.

The average rate of warming for each test can be calculated from the curves shown in Figure 8. Thus, for trials showing higher resolution (c40, c50 and c60) test times are between $3.550 \mathrm{~s}$ (something less than 1 hour) and the $5.080 \mathrm{~s}$ (less than hour and a half). Those times, taking into account the range of the test temperature is $35-300{ }^{\circ} \mathrm{C}$, give rise to very high heating speeds: $\mathrm{c} 40$, speed is $4.5^{\circ} \mathrm{C} \mathrm{min}^{-1}$ for $\mathrm{c} 50$ is $3.7^{\circ} \mathrm{Cmin}^{-1}$ for c60 is $3.1^{\circ} \mathrm{Cmin}^{-1}$

From these results to work with the maximum possible mass is recommended. In the studied case for hydrated cement samples working with $60 \mathrm{mg}$ is suggested.

\subsection{REPRODUCIBILITY OF RESULTS}

Figure 9 shows the comparison between two curves obtained with the same sample and the same parameters of thermogravimetric analysis $(60 \pm 1 \mathrm{mg}$, without purge gas)

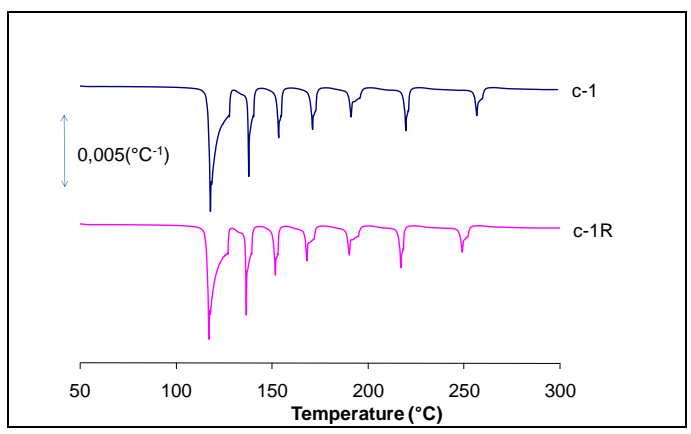

Figure 9. Test reproducibility (HRTG) in samples of hydrated cement.

The same number of events is detected, encountered with slight differences in the temperature corresponding to the maximum mass loss rates $\left(\mathrm{T}_{\mathrm{i}}^{\max }\right)$. Table 3 shows the values of $T_{i}{ }^{\max }$ as well as loss of mass rates $\left(\mathrm{P}_{\mathrm{i}}^{\max }\right)$ associated with each peak and the percentages of loss mass $\mathrm{X}_{\mathrm{i}}$ attributed to each peak.
Table 3. Parameters of the decompositions in HRTG

\begin{tabular}{|l|c|c|c|c|c|c|}
\hline Peaks & \multicolumn{3}{|c|}{ C-1 } & \multicolumn{3}{c|}{ C-1R } \\
\hline & $\mathrm{T}_{\mathrm{i}}^{\text {max }}$ & $\mathrm{P}_{\mathrm{i}}^{\text {max }}$ & $\mathrm{X}_{\mathrm{i}}$ & $\mathrm{T}_{\mathrm{i}}^{\text {max }}$ & $\mathrm{P}_{\mathrm{i}}^{\text {max }}$ & $\mathrm{X}_{\mathrm{i}}$ \\
\hline 1 & 117,9 & 54,3 & 4,8 & 117,1 & 39,4 & 4,5 \\
\hline 2 & 137,8 & 45,5 & 1,4 & 136,6 & 35,3 & 1,5 \\
\hline 3 & 153,3 & 15,8 & 1,2 & 151,6 & 22,2 & 1,1 \\
\hline 4 & 170,9 & 16,6 & 1,1 & 167,9 & 20,0 & 1,1 \\
\hline 5 & 191,0 & 16,1 & 1,1 & 190,0 & 13,6 & 1,2 \\
\hline 6 & 219,6 & 15,8 & 1,1 & 217,0 & 23,1 & 1,0 \\
\hline 7 & 256,2 & 11,5 & 0,9 & 248,8 & 15,0 & 0,8 \\
\hline Total & & & 12,8 & & & 12,5 \\
\hline
\end{tabular}

$\mathrm{T}_{\mathrm{i}}^{\max }$ and $\mathrm{X}_{\mathrm{i}}$ have practically equal values for the two curves (C-1 and C-1R). However, $\mathrm{P}_{\mathrm{i}}^{\max }$ has slight differences. For these reasons, it is possible assert that for studied material, the reproducibility is very high in size and position of the peaks for proposed parameters.

\section{CONCLUSIONS}

The technique of high-resolution thermogravimetry (HRTG) is a highly efficient method to separate reactions of decomposition that overlap in thermal analysis of materials as hydrated Portland cement.

The resolution obtained is heavily dependent of the sample mass. We recommend working with $60 \mathrm{mg}$ for Portland cement pastes for the used equipment. The resolution is significantly better when purge gas is not used.

Using the selected parameters gets an excellent reproducibility of results in the thermograms. In addition, test times are 
adequate, due to that the average warming rates are higher than the $3{ }^{\circ} \mathrm{C} \cdot \mathrm{min}^{-1}$ for the studied temperature range.

\section{ACKNOWLEDGEMENT}

The authors expressed their thanks Cementos ARGOS S. A. and COLCIENCIAS (project 20201007768) of Colombia for their economic support for the realization of this research. The authors would also like to thank to MICINN (Spanish Ministry of Science and Innovation) for the project BIA2007-63252 with FEDER co-financing.

\section{REFERENCES}

1. M. V. Borrachero, J. Payá, M. Bonilla and J. Monzó. The use of thermogravimetric analysis technique for the characterization of construction materials: The gypsum case. Journal of Thermal Analysis and Calorimetry, Vol. 91 (2008) 2, 503-509.

2. V. S. Ramachandran, R. M. Paroli, J. J. Beaudoin \& A. H. Delgado. Thermal analysis of construction materials. Bulding Materials Series. Noyes Publications, New York, 2003. 679p.

3. VS Ramachandran, Application of Differential Thermal Analysis in Cement Chemistry, Chemical Publishing Co., Inc., New York, 1969

4. S,Vechio, A. La Ginestra, A. Frezza and C.Ferragine, Thermochimica Acta, 227(1993)215

5. M.Anastiasiou, Yh. Hasapis, T.Zorba, E.Pavlidou, K.Chfissafis, and K. M. Parasakevopoulos, Journal of Thermal Analysis and Calorimetry, 84(2006)27

6. M. E. Brown, Introduction to thermal analysis technique and applications, Chapman and Hall (1998).

7. R. Riesen. Adjustement of heating rate for maximun resolution in TG and TMA (MaxRes). Journal of
Thermal Analysis and Calorimetry, Vol 53 (1998) 365 - 374.

8. P.J.Haines, "Thermal Methods of analysis, Blackie Academic Professional (1995)

9. .Dweck, P.M.Büchler, A.C.V.Celho and F.K.Cartledge, Thermochimica Acta, 346(2000)105

10. JB. Pacewska, I.Wilinska, M.Bukowska, G.Blonkowski and W.Nocun-Wczelik, Journal of Thermal Analysis and Calorimetry., 77(2004)133

11. J.Payá, J. Monzó, M.V.Borrachero, S.Velazquez, Cement and Concrete Research, 33(2003)603

12. C.A.Pinto, P.M.Büchler and J.Dweck, Journal of Thermal Analysis and Calorimetry., 87(2007)715

13. M.F: Rojas and J.Cabrera, Cement and Concrete Research, 32(2002)133

14. J.Dweck, P. F. Ferreira Da Silva, R.Silva Aderne, P. M. Büchler and F. K. Cartledge. Journal of Thermal Analysis and Calorimetry, 71(2003)821

15. J.M.Criado, L.A.Pérez-Maqueda, M.J.Diánez and P.E.SánchezJiménez., Journal of Thermal Analysis and Calorimetry, 87(2007)297

16. P. S. Gill, S. R. Sauerbrunn and B. S. Crowe. High resolution thermogravimetry. Journal of Thermal Analysis and Calorimetry, Vol. 38 (1992) 255-266. 